\title{
APLICAÇÃO DE CLAE-DAD-EM/EM NA CARACTERIZAÇÃO ESTRUTURAL DE ALCALOIDES ISOLADOS DE Prosopis juliflora, ATIVIDADE ANTICOLINESTERÁSICA E ANTI-HELMÍNTICA
}

\author{
Kelli de Oliveira Carneiro'; Alexsandro Branco²; Hélimar Gonçalves de Lima ${ }^{3}$; \\ Maria José Moreira Batatinha ${ }^{4}$ e Mariana Borges Botura ${ }^{5}$ \\ 1. Bolsista PIBIC/CNPQ, Graduanda do curso de Farmácia, Universidade Estadual de Feira de Santana, e-mail: \\ kelli.farmacia27@gmail.com \\ 2. Orientador, Departamento de saúde, Universidade Estadual de Feira de Santana, e-mail: brnaco@uefs.br \\ 3. Participante do projeto, Departamento de anatomia, patologia e clínicas, Universidade Federal da Bahia, e-mail: \\ helima_vet@hotmail.com \\ 4. Participante do projeto, Departamento de anatomia, patologia e clínicas, Universidade Federal da Bahia, e-mail: \\ mjmb12345@gmail.com \\ 5. Participante do projeto, Departamento de saúde, Universidade Estadual de Feira de Santana, e-mail: \\ mbbotura@hotmail.com
}

\section{PALAVRAS-CHAVE: Atividade Anticolinesterásica; Prosopis juliflora; Leguminosae.}

\section{INTRODUÇÃO}

$\mathrm{Na}$ busca por novos fármacos, os produtos naturais destacam-se pela diversidade estrutural e, assim, as espécies vegetais são candidatas importantes para screening de novos compostos bioativos (GIORDANI et al.,2008).

Alcaloides são compostos nitrogenados com pouca distribuição na natureza. Estes compostos já foram identificados na espécie Prosopis juliflora em estudos anteriores e são conhecidos pelo potente efeito fisiológico sobre o organismo e o sistema dos mamíferos, constituindo importantes agentes terapêuticos. Como representantes dessa gama de compostos que são usados para o tratamento de doenças, podemos citar a atropina, morfina, quinina e vincristina (ROBBERS; SPEEDIE; TYLER, 1997).

As parasitoses gastrintestinais são consideradas um importante fator limitante para a caprinocultura, uma vez que promovem redução da produtividade animal devido à perda de peso, diminuição no consumo alimentar, diarreia, anemia, queda na produção de leite, baixa fertilidade e elevada mortalidade em caso de alta taxa de infecção, conduzindo à perda econômica na produção (LIMA et al., 2010; VILELA et al., 2012).

As doenças degenerativas, como Alzheimer, tornam-se mais frequentes com o aumento da expectativa de vida da população. Os avanços obtidos na compreensão da evolução da doença têm demonstrado que o uso de inibidores da enzima acetilcolinesterase (AChE) é a forma mais eficiente de controle da doença (YAMAGUCH, 2012). Nesse sentido, a busca por novos compostos com atividade anticolinesterásica é de grande importância o que justifica a realização do trabalho que tem como objetivo avaliar a atividade anticolinesterásica e antihelmíntica de alcaloides isolados da espécie Prosopis juliflora.

\section{MATERIAIS E MÉTODOS}

Obtenção dos extratos: O extrato hexânico foi obtido por maceração do material pulverizado em hexano, separadamente, por três extrações consecutivas, por 72 horas cada. O extrato metanólico e acetato de etila foram obtidos pelo mesmo processo descrito, substituindo o solvente. O filtrado obtido em cada etapa foi reunido e o volume reduzido em rotaevaporador. 
Obtenção da fração rica em alcaloides: o extrato etanólico, após ter o volume reduzido, foi submetido à partição líquido-líquido. Passo 1: em um funil de separação o extrato foi acidificado até pH 3 com uma solução de $\mathrm{HCl}$ a 2\%; passo 2: o extrato acidificado foi submetido a três extrações com clorofórmio; passo 3: no funil de separação a fase aquosa foi basificada até pH 11 com NH4OH e submetida a nova extração com clorofórmio (obtenção da fração rica em alcaloides); passo 4: a fração rica em alcaloides foi seca com sulfato de sódio anidro (Na2SO4) e teve seu volume reduzido em rotaevaporar, conservado em capela para a retirada de todo o solvente.

Avaliação da atividade anticolinesterásica: a enzima utilizada foi a acetilcolinesterase (AChE) de Electrophorus electricustipo VI (sigma). Em cada posso das microplacas (96 poços) foram adicionados $25 \mu \mathrm{L}$ de iodeto de acetilcolina $15 \mathrm{mM}, 125 \mu \mathrm{L}$ de DTNB, $50 \mu \mathrm{L}$ de tampão Tris$\mathrm{HCl} 50 \mathrm{mM}$ pH 8,0, contendo 0,1\% de BSA (Albumina do Soro Bovino) e $25 \mu \mathrm{L}$ da fração de alcaloide obtida de Prosopis juliflora em diferentes concentrações. A absorbância foi medida a $405 \mathrm{~nm}$ em leitor de microplaca a cada $13 \mathrm{~s}$ por 5 vezes. Em seguida foram adicionados 25 $\mu \mathrm{L}$ da enzima $(0,22 \mathrm{U} / \mathrm{mL})$, e a absorbância foi medida novamente a cada 13 s por 8 vezes.

Atividade anti-helmíntica: foi depositado a cada poço da microplaca (96 poços) $100 \mu \mathrm{L}$ da suspensão de ovos de nematoides gastrintestinais de caprinos e adicionado o mesmo volume do extrato acetato de etila e fração de alcaloides das vagens de P. juliflora diluídos em DMSO $(0,5 \%)$, nas concentrações de 4,0;2,67; 1,78; 1,19 e $0,79 \mathrm{mg} / \mathrm{mL}$. Também foi adicionado meio nutritivo na proporção de $7 \%$ do volume total. Foram utilizados DMSO $(0,5 \%)$ e tiabendazol $(0,05 \mathrm{mg} / \mathrm{mL})$ como controles negativo e positivo, respectivamente. Após incubação das placas em estufa B.O.D. a $24^{\circ} \mathrm{C}$ por 48 horas acrescentou-se lugol para interromper a reação, e todos os ovos e larvas foram contados em cada poço. Três repetições com cinco replicatas foram realizados para cada concentração e controles.

\section{RESULTADOS E DISCUSSÃO}

Para a atividade anticolinesterásica a menor concentração apresentou $14 \%$ de inibição da enzima acetilcolinesterase enquanto a maior apresentou 83,5\% de inibição. Segundo Eldeen et al (2005) a atividade anticolinesterásica realizada com extratos é considerada moderada quando apresenta valores menores que $60 \%$. Além disso, extratos cuja inibição enzimática apresente valores maiores ou iguais a $50 \%$ devem ser considerados para fracionamentos e isolamento dos princípios ativos capazes de inibir a enzima acetilcolinesterase, o que torna o extrato metanólico de algaroba promissor para ter seus constituintes purificados e identificados para testes posteriores e identificação dos compostos responsáveis pela atividade (TREVISAN; MACEDO, 2001).

O resultado do teste de inibição da eclosão de ovos de nematoides gastrintestinais de caprinos mostrou-se dose dependente, ou seja, quanto maior a concentração, maior a inibição da eclosão dos ovos. Para o extrato foi observado inibição de $90 \%$ na concentração de $4 \mathrm{mg} / \mathrm{mL}$ enquanto que para a fração rica em alcaloides observou-se inibição de $90 \%$ desde a concentração $1,78 \mathrm{mg} / \mathrm{mL}$. Esta maior atividade da fração rica em alcaloides pode ser justificada pela atividade tóxica conhecida dos alcaloides, além disso, a composição complexa do extrato apresenta, além das substâncias ativas, substâncias sem atividade frente ao teste.

A fração rica em alcaloides foi submetida à Cromatografia à Líquidos de Alta Eficiência acoplada ao espectro de massas (CLAE-ME). O estudo de elucidação estrutural dos 
compostos presentes na fração rica em alcaloides esta em andamento, mas já foi possível a identificação de três alcaloides: prosopina, juliprosopina e juliprosina.

O cromatograma (figura1) apresentou no pico 1 o íon pseudomolecular com m/z $326[\mathrm{M}+\mathrm{H}]+$ em 13,4 minutos que corresponde ao alcaloide prosopina o pico 2 apresentou íon pseudomolecular com m/z $627[\mathrm{M}+\mathrm{H}]+$ em 13,7 minutos que corresponde ao alcaloide juliprosina; Em 15 minutos, apresentou o íon pseudomolecular com m/z $630[\mathrm{M}+\mathrm{H}]+$, que corresponde ao alcaloide juliprosopina. É possível afirmar a identificação destes alcaloides por já terem sido descritos na literatura anteriormente.

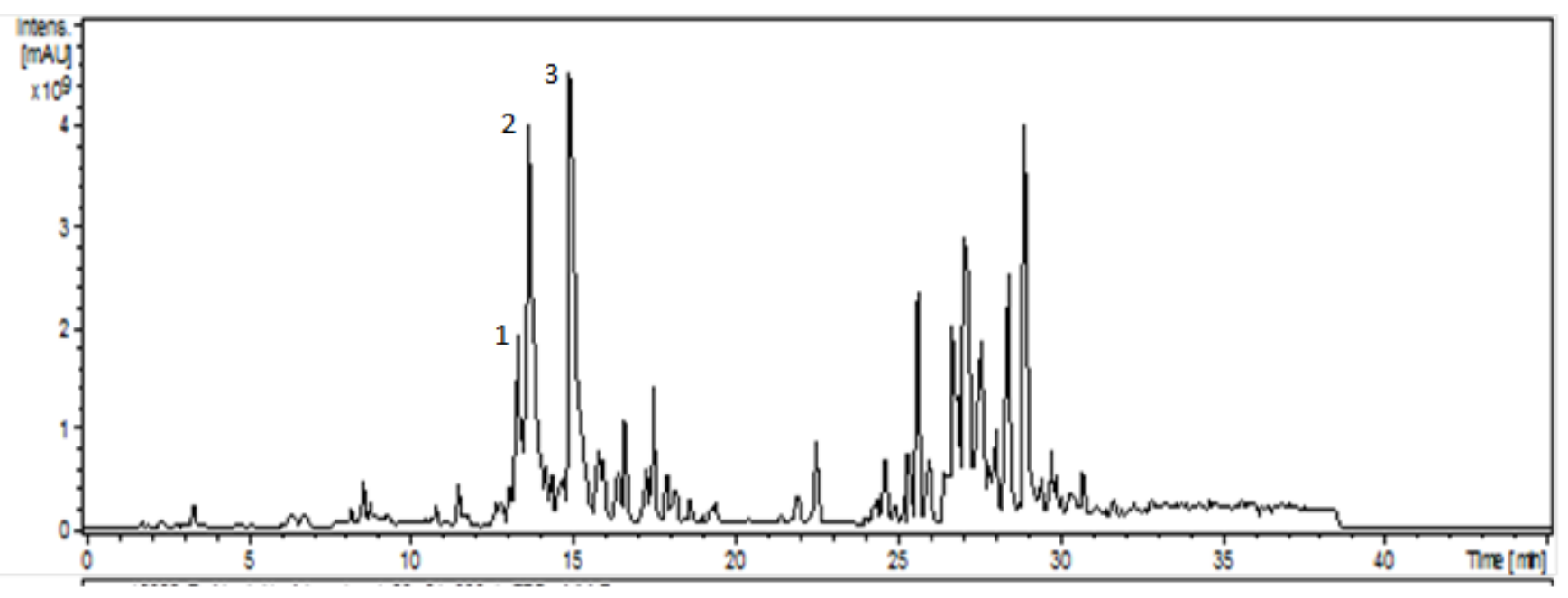

Figura 1. Cromatograma da fração rica em alcaoides.

O íon pseudomolecular com m/z 316 apresentou, quando submetidos ao $\mathrm{MS}_{2}$, um fragmento em 298, formado pela perda de uma molécula de água e outro em 280 , referente à perda de duas moléculas de água, esse perfil foi descrito por Singh e Verma, 2012 para o alcaloide prosopina.

$\mathrm{O}$ íon pseudomolecular com m/z 627 quando submetido ao $\mathrm{MS}_{2}$ apresentou m/z $314[\mathrm{M}+\mathrm{H}]^{+}$ o que indica que não houve fragmentação, apenas foi adicionado mais um próton ao íon pseudomolecular. $\mathrm{O}$ mesmo acontece com o íon pseudomolecular com $\mathrm{m} / \mathrm{z}$ 630, quando submetido ao $\mathrm{MS}_{2}$ apresentou $\mathrm{m} / \mathrm{z} 315[\mathrm{M}+\mathrm{H}]^{+}$. Esse comportamento frente à CLAE-MS desses alcaloides foi descrito por SANTOS et al, 2013.

\section{CONSIDERAÇÕES FINAIS}

O estudo possibilitou a identificação de três alcaloides presentes na espécie Prosopis juliflora, além de demonstrar o potencial da espécie frente às atividades anti-helmíntica e acetilcolinesterase. O extrato acetato de etila de Prosopis juliflora e a fração rica em alcaloides mostraram-se ativas para a atividade anti-helmíntica. Esta atividade pode ser atribuída aos alcaloides presentes no extrato, pois quando testada, a fração rica em alcaloides demostrou atividade ainda maior que ha presente no extrato. $\mathrm{O}$ extrato metanólico de prosopis juliflora apresenta potencial frente à atividade anticolinesterásica, sendo necessários estudos posteriores para o possível isolamento, purificação e identificação dos compostos responsáveis por essa atividade. Com isso, será necessário a realização do teste da atividade 
anticolinesterásica na fração rica em alcaloides. Além da identificação dos outros constituintes presentes nesta fração.

\section{REFERÊNCIAS}

PINTO, A. C.et al. Produtos Naturais: Atualidade, Desafios e Perspectivas. Química nova. [S. 1.], v.25, n. 1, p. 45-61, 2002. Disponível em:< http://www.scielo.br/scielo.php?script=sci_ar ttext\&pid=S0100-40422002000800009>. Acesso em: 2 abr, 2015.

ROBBERS, J. E.; SPEEDIE, M. K.; TYLER, V. E. Farmacognosia e Farmacobiotecnologia. 1997.

TREVISAN, M.T.S.; MACEDO, F.V.V. Seleção de plantas com atividade anticolinesterase para tratamento da doença de Alzheimer. Química Nova, v.26, n.3, p.301-304, 2003.

Disponível em: < http://submission .quimicanova.sbq.org.br/qn/qnol/2003/vol26n3/01.pdf>. Acesso em: 24 jul. 2017.

VIEGAS JR, C.; BOLZANI, V. B.; FURLAN, M.; FRAGA, C. A. M; BARREIRO, E. J. Produtos naturais como candidatos a fármacos úteis no tratamento do mal de Alzheimer.

Química Nova, v. 27, p. 655-660, 2004.

ELDEEN, S. M. I.; ELGORASHI, E. E.; STADEN, J. Antibacterial, anti-inflammatory, anticholinesterase and mutagenic effects of extracts obtained from some trees used in South African traditional medicine. Journal of Ethnopharmacology, v. 102, p. 457- 464, 2005. Disponível em: https://sci-hub.cc/10.1 016/ j.jep.2005.08.049. Acesso em: 24 jul. 2017. LIMA, M.M.; FARIAS, M.P.O.; ROMEIRO, E.T.; FERREIRA, D.R.A.; ALVES, L.C.; FAUSTINO, M.A.G. Eficácia da moxidectina, ivermectina e albendazole contra helmintos gastrintestinais em propriedades de criação caprina e ovina no Estado de Pernambuco.

Ciência Animal Brasileira, v. 11, n. 1, p.94-100, 2010.

YAMAGUCH , K. K. L.; ALCÂNTARA1 , J. M.; VEIGA, V. F. Investigação do potencial antioxidante e anticolinesterásico de 20 espécies da família Lauraceae. Acta Amazonica, v. 42, n. 4, 2011.

VILELA, V.L.R.; FEITOSA, T.F.; LINHARES, E.F.; ATHAYDE, A.C.R.; MOLENTO, M.B.; AZEVEDO, S.S. FAMACHA. Method as na auxiliary strategy in the control of gastrointestinal helminthiasis of dairy goats under semiarid conditions of Northeastern Brazil. Veterinary Parasitology, v. 190, p. 281-284, 2012.

SANTOS, E.T. et al. Antibacterial Activity of the Alkaloid-Enriched Extract from Prosopis juliflora Pods and Its Influence on in Vitro Ruminal Digestion. International journal of Molecular Sciences. v. 14. n. 4. 2013. Disponível em: < http://www.mdpi.com/14220067/14/4/8496/htm>. Acesso em: 25 jul. 2017. 